\title{
A Mechanism of Release of Calreticulin from Cells During Apoptosis
}

\author{
Joanna M. Tarr ${ }^{1}$, Philip J. Young ${ }^{1}$, Robert Morse ${ }^{1}$, Debra J. Shaw ${ }^{1}$, \\ Richard Haigh $^{1,2}$, Peter G. Petrov ${ }^{3}$, Steven J. Johnson ${ }^{4}$, \\ Paul G. Winyard ${ }^{1}$ and Paul Eggleton ${ }^{1 *}$
}

\author{
${ }^{1}$ Peninsula Medical School, \\ University of Exeter, \\ Exeter EX1 2LU, UK \\ ${ }^{2}$ Princess Elizabeth Orthopaedic \\ Centre, Royal Devon and Exeter \\ Foundation Trust Hospital, \\ Exeter, EX2 5DW, UK \\ ${ }^{3}$ School of Physics, University of \\ Exeter, Exeter EX4 4QL, UK \\ ${ }^{4}$ Sir William Dunn School of \\ Pathology, University of \\ Oxford, Oxford OX1 3RE, UK \\ Received 15 March 2010; \\ received in revised form \\ 25 June 2010; \\ accepted 30 June 2010
}

\begin{abstract}
Calreticulin (CRT) is an endoplasmic reticulum (ER) chaperone responsible for glycoprotein folding and $\mathrm{Ca}^{2+}$ homeostasis. CRT also has extracellular functions, e.g. tumor and apoptotic cell recognition and wound healing, but the mechanism of CRT extracellular release is unknown. Cytosolic localization of CRT is determined by signal peptide and subsequent retrotranslocation of CRT into the cytoplasm. Here, we show that under apoptotic stress conditions, the cytosolic concentration of CRT increases and associates with phosphatidylserine (PS) in a $\mathrm{Ca}^{2+}$-dependent manner. PS distribution is regulated by aminophospholipid translocase (APLT), which maintains PS on the cytosolic side of the cell membrane. APLT is sensitive to redox modifications of its $\mathrm{SH}$ groups by reactive nitrogen species. During apoptosis, both CRT expression and the concentration of nitric oxide (NO) increase. By using S-nitroso-L-cysteine-ethyl-ester, an intracellular NO donor and inhibitor of APLT, we showed that PS and CRT externalization occurred together in an S-nitrosothiol-dependent and caspase-independent manner. Furthermore, the CRT and PS are relocated as punctate clusters on the cell surface. Thus, CRT induced nitrosylation and its externalization with PS could explain how CRT acts as a bridging molecule during apoptotic cell clearance.
\end{abstract}

Edited by J. Karn

Keywords: cell recognition; calreticulin-phosphatidylserine interaction; endoplasmic reticulum; protein secretion

\section{Introduction}

Calreticulin (CRT) is the most abundant calciumbinding protein in the lumen of the endoplasmic reticulum (ER) of all nucleated cells and is involved in many intracellular and extracellular processes. ${ }^{1-3}$ In the ER, CRT has a number of functions, including $\mathrm{Ca}^{2+}$ sensing, protein folding and a role in MHC class I assembly. The multifunctional nature of CRT suggests that it may be prevalent in many cellular

${ }^{*}$ Corresponding author. E-mail address:

paul.eggleton@pms.ac.uk.

Abbreviations used: APLT, aminophospholipid translocase; CRT, calreticulin; FasL, Fas ligand (CD95L); GFP, green fluorescent protein; FITC, fluorescein isothiocyanate; PDI, protein disulfide isomerase; PC, phosphatidylcholine; PS, phosphatidylserine; ROS, reactive oxygen species; SNCEE, S-nitroso-L-cysteine ethyl ester; PLSCR1, phospholipid scramblase 1. compartments. Recent work has explained, in part, how CRT translocates from the ER to the cytosol, ${ }^{5}$ where it undergoes arginylation. ${ }^{6}$ During cell stress, both CRT expression and the concentration of nitric oxide (NO) increase and CRT is released from cells by unknown mechanisms. ${ }^{7,8}$ Immunological evidence that CRT is released from cells comes from a number of autoimmune conditions that present with CRT autoantibodies. ${ }^{9,10}$ Cell surface expression of CRT might require post-translational modification of the protein, e.g. cleavage of its C-terminal KDELbased ER retrieval sequence, or CRT interaction with other proteins that mask the retrieval sequence. In support of this hypothesis, a number of truncated forms of CRT have been found that might explain how CRT leaves the cell. ${ }^{11}$ Proteolysis studies have shown that the $\mathrm{NH}_{2}$-terminal half of CRT lacking the KDEL sequence is resistant to proteolysis in the presence of physiological concentrations of $\mathrm{Ca}^{2+} \cdot{ }^{12,13}$ The ER is a site of reactive oxygen species (ROS) production, but has few anti-oxidant defenses. 
During cell stress, CRT is susceptible to oxidative modifications, such as carbonylation, which might affect its retention in the ER. ${ }^{14}$ CRT acts as a $\mathrm{Ca}^{2+}$ store in the ER. The translocation of CRT to the cytosol or extracellular environment might influence the process of apoptosis that is regulated by free $\mathrm{Ca}^{2+}$. The importance of CRT in apoptotic regulation of cell death is supported by the observation that CRT-deficient cells are more resistant to apoptosis than cells induced to over-express CRT. ${ }^{15}$

The relevance of extracellular CRT in human health and disease is substantial. Recent studies have shown that CRT plays a major role in tumor recognition, wound healing and enhancing the clearance of apoptotic cell debris. ${ }^{16-18}$ Our studies have shown that patients with autoimmune diseases have a greater accumulation of CRT in their circulation, indicating an increased release of CRT during cell stress. ${ }^{19}$

The current study provides evidence of the redistribution of CRT within human Jurkat $\mathrm{T}$ cells during stress conditions, as occurs during apoptosis. We demonstrate that CRT is present on the surface of both pre-apoptotic and Fas (CD95)-mediated apoptotic cells to varying degrees. Stimulation of CD95 with soluble Fas ligand (FasL or CD95L) is known to lead to receptor aggregation within PS-enriched lipid rafts, in association with Fas-associated death domain-containing protein (FADD). FADD can interact with procaspase-8, forming the multi-protein death-inducing signaling complex (DISC), which drives cells towards apoptosis. ${ }^{20}$ Earlier, we showed that CRT is associated with lipid rafts, ${ }^{21}$ and can interact with FasL to prevent CD95-mediated apoptotic death in Jurkat T cells. ${ }^{22}$ In this study we show that CRT binds predominantly to PS in a $\mathrm{Ca}^{2+}$ dependent manner. The release of CRT occurs in concert with PS externalization in a caspase 3independent manner upon transnitrosylation of aminophospholipid translocase (APLT) by S-nitrosothiols. Our novel results explain how CRT can be released in a regulated manner from cells undergoing nitrosative stress via $S$-nitrosylation/oxidation of the SH groups of APLT by intracellular $\mathrm{NO}$ released from an NO donor. The inhibition of APLT leads to PS externalization in association with CRT. Given the importance of extracellular CRT for tumor and apoptotic cell recognition and wound healing, the ability to manipulate the release of CRT in a noncaspase-dependent manner might have important implications for the resolution of inflammation.

\section{Results}

\section{Presence of plasma membrane-associated CRT and its release from resting and apoptotic cells}

CRT has been reported on the surface of various eukaryotic cells. ${ }^{4}$ Initially, we investigated whether CRT is expressed non-specifically together with other ER proteins on the extracellular surface of
Jurkat T cells. Untreated and apoptotic (treated with $25 \mathrm{ng} / \mathrm{ml}$ FasL) cells were labeled with biotin for the purpose of isolating membrane proteins. Equal amounts $(30 \mu \mathrm{g})$ of biotin-labeled plasma membrane (PM) proteins and total cell lysates, as determined by nanodrop spectrophotometry, were transferred onto a number of polyvinylidene fluoride membranes (Fig. 1a). Control blots were probed with anti-biotinHRP to ensure equal loading (Fig. 1a, right-hand panel). In addition, as HSP70 is known to be present in the cytosol and PM of cells, anti-HSP70 was used to check for equal sample transfer of PM and cell lysate (CL) preparations onto the immunoblots. Then blots were immunoblotted with antibodies against the ER proteins CRT, calnexin, protein disulfide isomerase (PDI) and KDEL peptide. As shown in Fig. 1a (lower panels), the anti-calnexin antibody produced a strong band at $90 \mathrm{kDa}$ (predicted molecular mass) in the CL. The anti-KDEL antibody produced bands at $78 \mathrm{kDa}$ and $94 \mathrm{kDa}$ (the predicted molecular mass of BIP (GRP78) and HSP90 (GRP94), respectively). The PDI antiserum detected a single protein of approximately $60 \mathrm{kDa}$. Immunoblotting with $\alpha$-CRT identified a single $60 \mathrm{kDa}$ band indicative of CRT on the PMs of apoptotic Jurkat cells but not resting cells (Fig. 1a, lanes 2 and 1, respectively) and in whole cell lysates from resting and FasL-treated Jurkat cells (Fig. 1a, lanes 3 and 4). Further experiments confirmed that Jurkat cells did not have the ER proteins calnexin or PDI on their cell surface. The KDEL antibody did not recognize CRT on the PM, indicating that a KDEL sequence is not exposed, possibly because of steric hindrance or because the KDEL sequence was not present on CRT at the cell surface. A final blot was probed with $\alpha$ biotin to confirm that multiple biotinylated PM proteins had been extracted (Fig. 1a right-hand panel). To confirm that CRT is predominantly present on Jurkat cells during apoptotic stress, the surface expression of CRT on intact cells was assessed by flow cytometry. Approximately $8.5 \%$ of untreated Jurkat cells were undergoing spontaneous apoptosis (as determined by annexin V staining and size) at any given time under the culture conditions used (Fig 1b, top left panel). These cells appeared smaller (7-8 $\mu \mathrm{m}$ diameter) compared with the non-apoptotic cells (9-13 $\mu \mathrm{m}$ diameter). The same population of cells expressed CRT on their cell surface (Fig 1b, top middle and right-hand panels). After treatment with FasL for $4 \mathrm{~h}, 24 \%$ of the Jurkat cells were assessed by annexin $\mathrm{V}$ staining as apoptotic, while $44 \%$ of the cells exhibited CRT on their cell surface (Fig 1b, bottom, middle and right-hand panels).

Immunoblots were used to monitor the release of CRT from Jurkat cells into the cell medium with and without treatment with digitonin. The application of digitonin at concentrations $\leq 50 \mu \mathrm{g} / \mathrm{ml}$ permeabilizes the plasma membrane of cells, leaving cytosolic organelles intact, while the use of a higher concentration of digitonin $(500 \mu \mathrm{g} / \mathrm{ml})$ solubilizes the remaining membrane-bound organelles. Only weak bands were apparent for the release of CRT from resting Jurkat cells (Fig. 2a, 
(a)
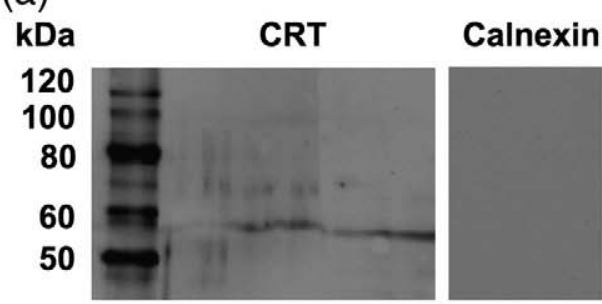

PDI

KDEL

HSP70 Biotin

Lanes -
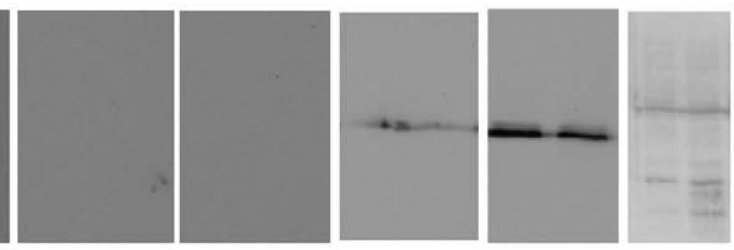

PM

CL

PM

PM

PM

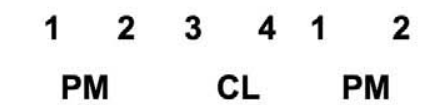

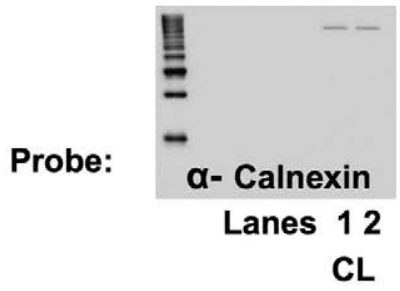

(b)
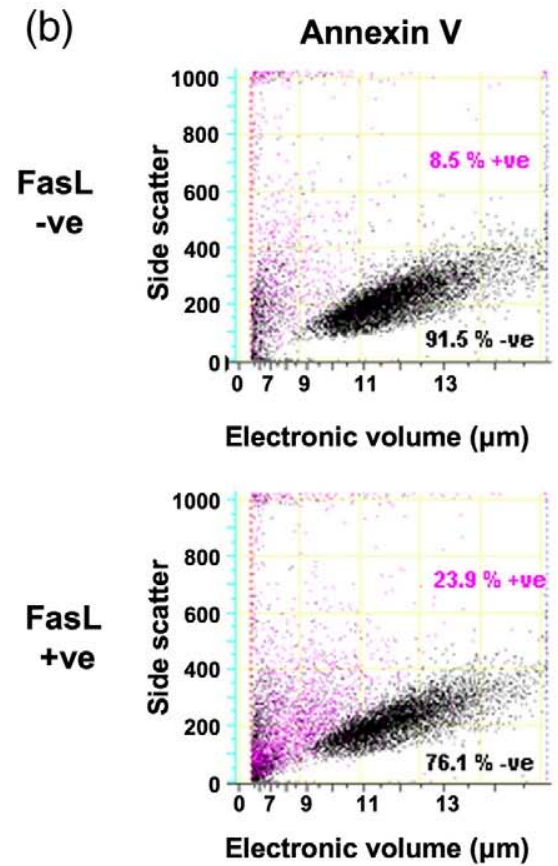
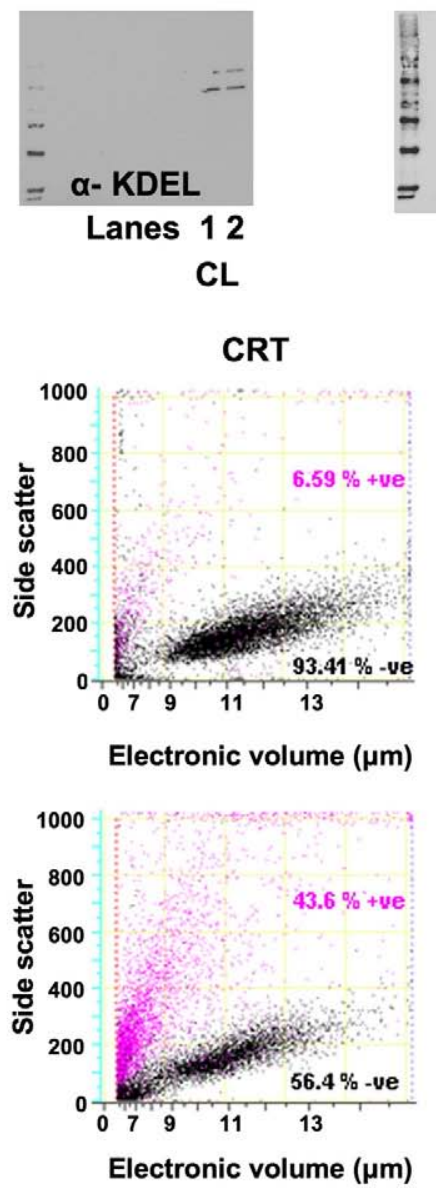

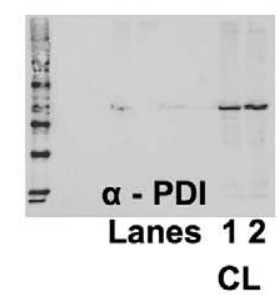

CL
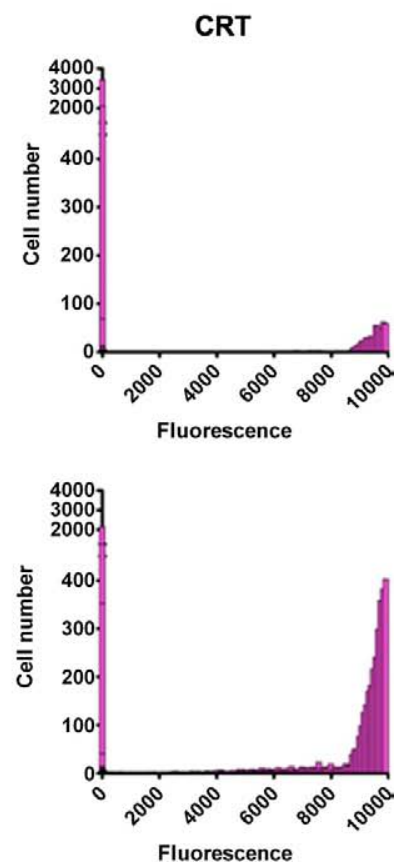

Fig. 1. Detection of CRT on the plasma membrane of Jurkat T cells (JKT). (a) Immunoblots were prepared of isolated biotinylated plasma membrane (PM) proteins from untreated (lane 1) and FasL-treated (lane 2) Jurkat cells. Equal gel loading was demonstrated by probing the PM blots with $\alpha$-biotin and $\alpha$-HSP70. Biotin-labeled PM extracts were probed with $\alpha$-human CRT, calnexin, PDI and KDEL. Control cell lysate (CL) preparations of untreated and FasL-treated cells confirmed each of the ER protein antibodies used to detect their specific intracellular proteins calnexin, KDEL and PDI (middle panel). Markers of 50-120 kDa are shown for the top panel. Markers for 20-120 kDa are shown for the lower panel. (b) Flow cytometric analysis of apoptotic Jurkat cells and surface CRT expression. Dot plots show the percentage of cells undergoing apoptosis under resting and FasL-treated conditions. Cells positive for annexin V staining and CRT surface expression are shown (pink) together with non-annexin V staining and CRT negatve expressing cells (black). The immunoblots and flow cytometric analysis are representative of three experiments.

lane 2), indicative of a small but detectable amount of CRT being released into the medium. This was marginally increased upon treatment with FasL (Fig 2a, lane 3). Cytosolic proteins can be released and tracked more readily by treating cells with $50 \mu \mathrm{g} / \mathrm{ml}$ of digitonin. ${ }^{23}$ The protein released into $\mathrm{Ca}^{2+}$-free cell medium from the equal cell numbers, pre- and post-digitonin treatment with and without
FasL was assessed by SDS-PAGE followed by immunoblotting with anti-calnexin or anti-CRT. The intracellular location of CRT (Fig. 2a) and calnexin (Fig. 2c) during FasL-induced apoptotic stress in Jurkat cells was tracked by treating cells with digitonin and the amounts of CRT released were monitored by densitometry (Fig. 2b). To prevent the released protein binding to the plasma 
(a)

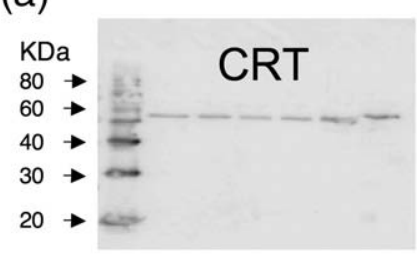

Lanes- $1 \quad 2 \quad 3 \quad 4 \quad 5 \quad 6 \quad 6$

(c)

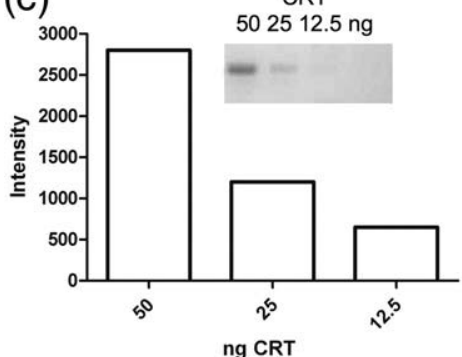

(b)

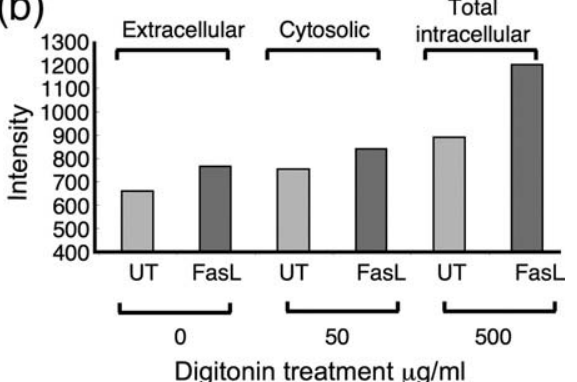

(d)

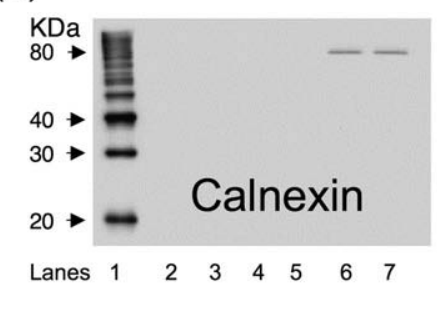

Fig. 2. Extracellular release under resting and apoptotic conditions and intra and extracellular location of CRT from digitonin treated cells. (a) Immunoblot analysis of spontaneous and digitonin release of CRT from cytosolic pools and total intracellular stores of $1 \times 10^{7}$ Jurkat cells (left-hand panel, lane 1 depicts western markers). Lanes 2, 4 and 6 represent CRT released from resting cells treated with 0,50 and $500 \mu \mathrm{g} / \mathrm{ml}$ digitonin, respectively. Lanes 3,5 and 7 represent cells treated with $25 \mathrm{ng} /$ $\mathrm{ml}$ FasL for $4 \mathrm{~h}$ and treated with 0 , 50 and $500 \mu \mathrm{g} / \mathrm{ml}$ digitonin, respectively. (b). A densitometry plot depicts the relative differences in release of CRT into the medium in comparison with (c) known amounts of CRT. (d) Calnexin release from Jurkat cells after digitonin treatment as described for a. The immunoblots are representative of three experiments.

membrane of cell lysates in a $\mathrm{Ca}^{2+}$-dependent manner, treatment with digitonin was done in the presence of $0.5 \mathrm{mM}$ EGTA. As a positive control of protein release from cytosolic organelles, we used a higher concentration of digitonin $(500 \mu \mathrm{g} / \mathrm{ml})$ to permeabilize and solubilize all the internal membranes of the cells. This demonstrated the additional release of non-cytoplasmic sources of CRT

(a) Synthesis of S-nitroso-L-cysteine-ethyl ester (SNCEE)<smiles>CCOC(=O)C(CS)[N-]Cl</smiles>

1<smiles>CCOC(=O)C([NH3+])CSN=O</smiles>

2<smiles>CCOC(=O)C(N)CSN=O</smiles>

1- L-cysteine ethyl ester hydrochloride

2- S-nitroso-L-cysteine ethyl ester hydrochloride

3- S-nitroso-L-cysteine ethyl ester

(b) Elemental analysis

\begin{tabular}{|l|l|}
\hline Element & Percentage \\
\hline Carbon & 31.775 \\
\hline Hydrogen & 5.53 \\
\hline Nitrogen & 9.365 \\
\hline Oxygen & 20.37 \\
\hline Sulphur & 16.445 \\
\hline Other & 16.515 \\
\hline
\end{tabular}

(c) EPR spectrum

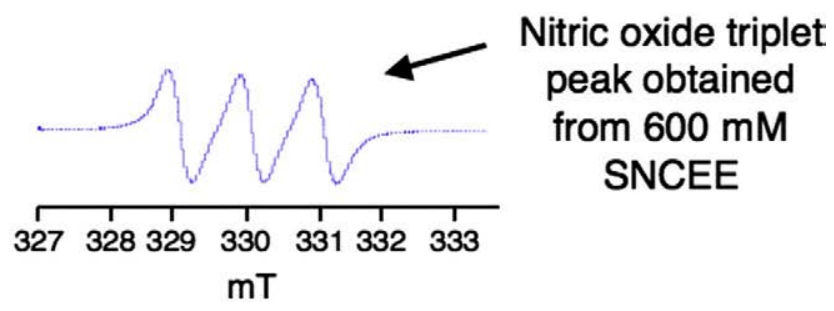

Fig. 3. Synthesis, analysis and release of nitric oxide from S-nitroso-L-cysteine ethyl ester (SNCEE). (a) SNCEE was prepared by direct $S$-nitrosation of the hydrochloride of L-cysteine ethyl ester (CEE:HCl) with ethyl nitrite. (b) Elemental analysis was performed to check the purity and chemical composition of SNCEE. (c) Electron paramagnetic resonance spectrum demonstrating the release of nitric oxide (NO) from the synthesised product, SNCEE. Synthesized SNCEE was decomposed in the presence of the $\mathrm{N}$-methyl-D-glucamine dithiocarbamate (MGD)-Fe ${ }^{2+}$ complex at alkaline $\mathrm{pH}$ and the $\mathrm{NO}$ released was spin trapped with (MGD) $)_{2}-\mathrm{Fe}^{2+}$ as described. ${ }^{59}$ The spectrum shows a typical NO-(MGD) $)_{2}-\mathrm{Fe}^{2+}$ triplet signal $\left(g=2.04\right.$ and $\left.a_{\mathrm{N}}=1.28 \mathrm{mT}\right)$. The spectrum was obtained with a JEOL JES RE1X spectrometer with the following acquisition parameters: microwave frequency, $9.43 \mathrm{GHz}$; microwave power, $4 \mathrm{~mW}$; centre field, $331.3 \mathrm{mT}$; sweep width, $4 \mathrm{mT}$; time constant 1s; sweep time, 80s; modulation frequency, $100 \mathrm{kHz}$ and modulation width, $0.1 \mathrm{mT}$. 
(Fig. 2a and b) and the release of the membranebound ER protein calnexin (Fig. 2c). Treatment of cells with $50 \mu \mathrm{g} / \mathrm{ml}$ or $500 \mu \mathrm{g} / \mathrm{ml}$ of digitonin increased the release of CRT from the cytosolic pool and ER pools of untreated and FasL-treated cells, respectively. Interestingly, the relative molecular mass of CRT released from Jurkat cells was $\sim 3-$ $5 \mathrm{kDa}$ smaller than that of the CRT present in the ER of FasL-stimulated cells. Calnexin was not detected in untreated cells or in cells treated with $50 \mu \mathrm{g} / \mathrm{ml}$ of digitonin, confirming the lack of penetration of the ER by digitonin at this lower concentration.

\section{Interaction of CRT with phosphatidylserine (PS) and release upon PS externalization}

We next hypothesized that CRT release might be increased during necrosis via breakdown of membrane integrity. Alternatively, PS might be involved in CRT release during PS externalization onto the outer surface of the PM during apoptosis. To address this, we studied the regulation of PS externalization by APLT. Experiments were done in which PS was induced to flip to the external side of the membrane without provoking a caspase 3dependent apoptotic event. We synthesized the NOproducing transnitrosylating agent $S$-nitroso-L-cysteine ethyl ester (SNCEE) as described (Fig. 3a). ${ }^{24}$ The composition and purity of the compound (Fig. 3b) were checked independently by elemental analysis (Elemental Microanalysis Ltd, Devon, UK). SNCEE enters cells rapidly and its ability to generate $\mathrm{NO}$ was determined by electron paramagnetic resonance as described, ${ }^{25}$ in which the typical NO triplet peak was observed as shown in Fig. 3c. APLT is sensitive to oxidation of its sulfhydryl groups by SNCEE. ${ }^{26}$ In earlier studies, SNCEE was shown to inhibit APLT activity directly and to increase scramblase activity threefold, ${ }^{27}$ leading to (a)

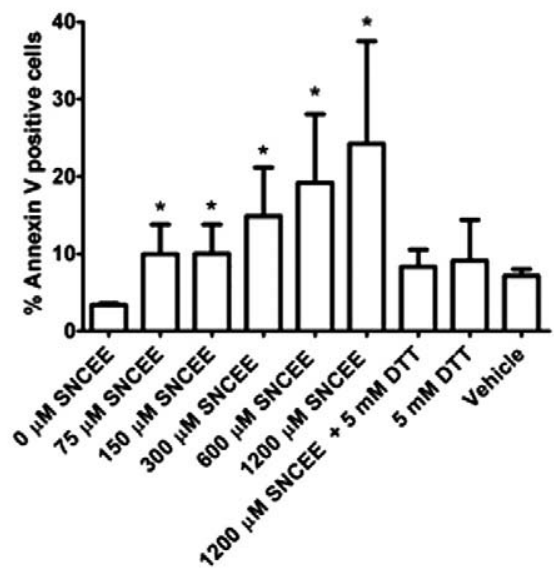

(c)

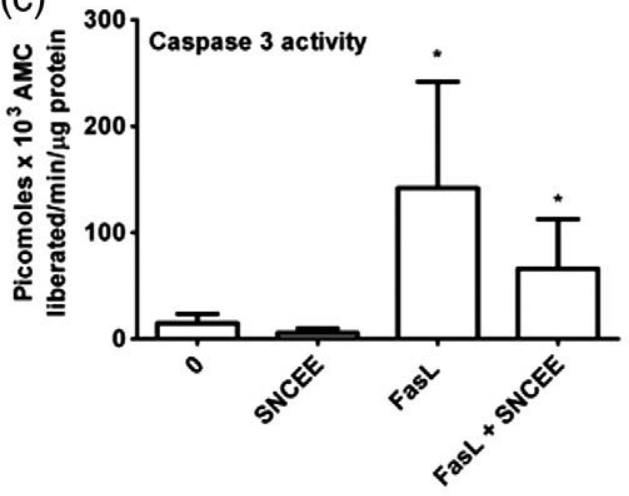

(b)

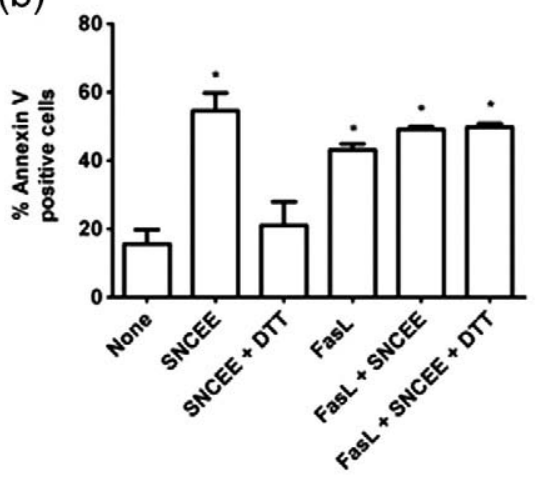

(d)

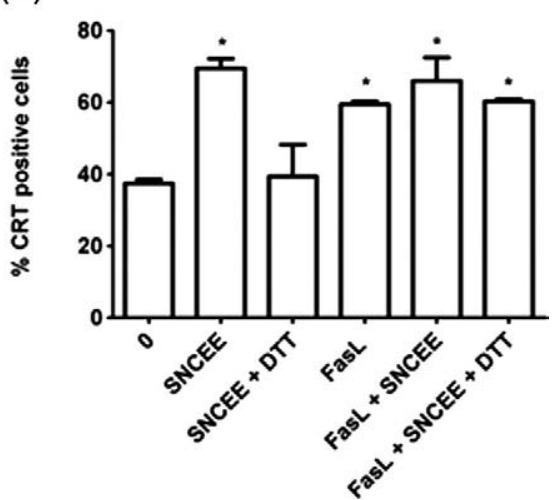

Fig. 4. PS externalization on the surface of Jurkat cells exposed to the transnitrosylating agent SNCEE leads to the presence of CRT on the cell surface. (a) Flow cytometric analysis of the concentration response effect of SNCEE on PS externalization (annexin V-positivity) on the surface of Jurkat cells and the ability to reverse the effect in the presence of DTT. The asterisk $(*)$ indicates a significant increase $(p<0.05)$ in annexin V binding compared with untreated control cells. Cells were treated with SNCEE for $30 \mathrm{~min}$ at $37^{\circ} \mathrm{C}$, washed and then stained with annexin V directly. Ethanol acted as a vehicle control for SNCEE. (b) Demonstration of PS externalization by $600 \mu \mathrm{M}$ SNCEE and $25 \mathrm{ng} / \mathrm{ml}$ FasL, or both, with and without DTT ( $5 \mathrm{mM}$ ) as detected by annexin V-positivity by flow cytometry. (c) Translocation of CRT in association with PS externalization induced by treatment with SNCEE or FasL occurred in a caspase 3-independent or dependent manner, respectively ( ${ }^{*} p<0.05$, FasL versus control, Mann-Whitney U test). (d) Extracellular CRT expression (anti-CRT positivity) in Jurkat cells treated with $600 \mu \mathrm{M}$ SNCEE with and without $5 \mathrm{mM}$ DTT or $25 \mathrm{ng} / \mathrm{ml}$ FasL. The control group represents cells without SNCEE treatment or FasL stimulation. ${ }^{*} p<0.05$, FasL versus control, SNCEE treatment \pm DTT versus control, Mann-Whitney $\mathrm{U}$ test. The value of each bar represents the mean $\pm \mathrm{SD}$ of three experiments. 
PS externalization. We used flow cytometry to quantify the numbers of cells with external PS and CRT after treatment of Jurkat cells with SNCEE. Cells treated with of 75-1200 $\mu \mathrm{M}$ SNCEE led to a sequential and statistically significant increase in extracellular PS as detected by annexin V staining (Fig. 4a). Treatment of Jurkat cells with $600 \mu \mathrm{M}$ SNCEE for $30 \mathrm{~min}$ was optimal for increasing the numbers of cells positive for surface PS by up to fourfold (Fig. 4b). To ascertain if the increase in external PS was due to S-nitrosylation of APLT in cells, experiments were done in the presence of the de-nitrosylating agent dithiothreitol (DTT), which was shown to reverse SNCEE-induced inhibition of APLT as indicated by the $50 \%$ reduction in external PS expression. Jurkat cells were treated with FasL for $4 \mathrm{~h}$ at $37^{\circ} \mathrm{C}$ leading to a threefold increase in cells positive for external PS, which was not inhibited by treatment with DTT. This was expected, because FasL-induced apoptosis is caspase 3-dependent when the denitrosylated form of the enzyme is active; ${ }^{28}$ therefore, DDT would be expected to enhance, not inhibit, the denitrosylation of caspase from its inactive $S$-nitrosylated state. We confirmed that cells exposed to SNCEE externalize PS in a caspase 3-independent manner (Fig. 4c). In contrast, FasL-induced apoptosis and PS externalization was caspase 3-dependent. CRT surface expression occurred in parallel with PS exposure in cells treated with SNCEE or Fas-L, demonstrating that the protein is clearly associated with PS surface expression irrespective of the mechanism of PS externalization (Fig. 4d). To exclude the possibility that CRT was not released from the cytosol and then attached to the cell-surface proteins rather than being transferred to the cell surface with PS, we did additional experiments on adherent HeLa cells transiently transfected with green fluorescent protein (GFP)-CRT. As shown in Fig. 5a, GFP-CRT transfected into HeLa cells was predominantly translocated to the ER, as confirmed employing a specific ER marker (ER-Tracker Blue DPX dye). As expected, GFP-CRT localized to distinct ER apoptotic blebs following treatment with $\mathrm{H}_{2} \mathrm{O}_{2}$ (Fig. 5b). The visual effect of SNCEE on externalization of PS and GFP-CRT is shown in Fig. 5c where, as expected, some untreated cells (possibly undergoing spontaneous apoptosis) showed patches of annexin $\mathrm{V}$ binding (red) on a few cells. In response to SNCEE, there was greater evidence of PS externalization on both GFP-CRT transfected and nontransfected cells. Both GFP-CRT and annexin V formed patches of fluorescence on the surface of SNCEE-treated HeLa cells. Importantly, GFP-CRT (a)

(b)
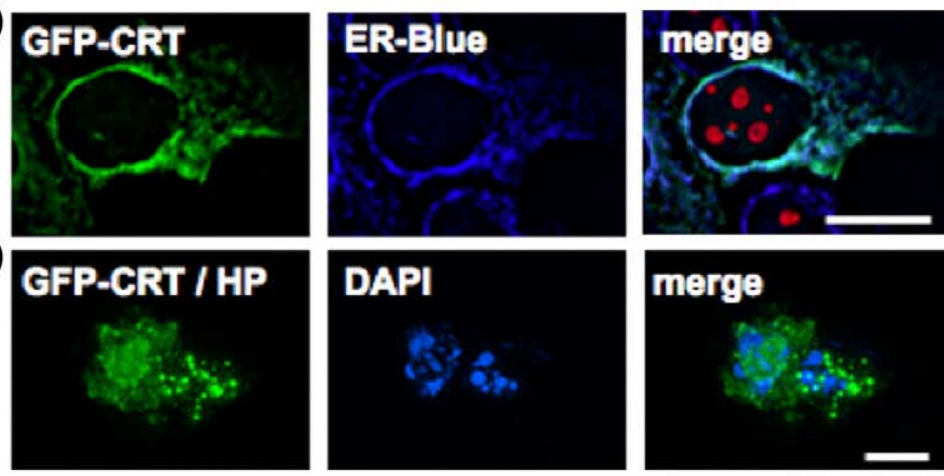

(c)

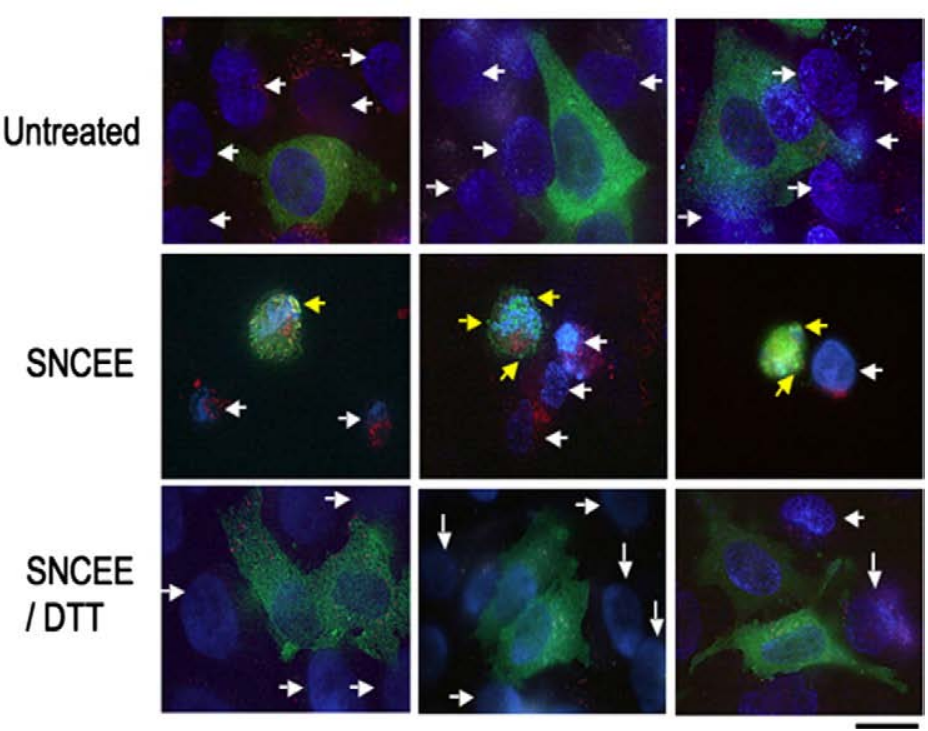

Fig. 5. Location of CRT in HeLa cells under resting, apoptotic and SNCEE-treated conditions. (a) GFPCRT proteins were efficiently targeted to the ER of HeLa cells. Cells were transiently transfected with full-length CRT and counterstained using ER-tracker (ER blue) and nucleoli were stained with ethidium bromide (red) under physiological conditions. (b) Subcellular localization of CRT during $\mathrm{H}_{2} \mathrm{O}_{2}$ -induced apoptosis. Targeting to apoptotic ER stress granules was monitored in HeLa cells expressing GFP-CRT after exposure to $1 \mathrm{mM}$ $\mathrm{H}_{2} \mathrm{O}_{2}$ for $6 \mathrm{~h}$. Nuclei were counterstained using DAPI (blue) to assess nuclear fragmentation. (c) PS externalization on the surface of HeLa cells exposed to SNCEE. The top panel shows three representative images of untreated HeLa cells transfected with GFP-CRT and counterstained with annexin V (red) and DAPI (blue). The white arrows show non-transfected cells. The middle panel shows three representative images of $\mathrm{HeLa}$ cells treated with SNCEE $(600 \mu \mathrm{M})$ for $30 \mathrm{~min}$ at $37^{\circ} \mathrm{C}$. The yellow arrows show externalization of CRT, where it is retained on the same cells in punctate raft-like aggregates. The bottom panel

shows cells treated with SNCEE $(600 \mu \mathrm{M})$ and DTT $(5 \mathrm{mM})$ simultaneously for $30 \mathrm{~min}$ at $37^{\circ} \mathrm{C}$. The scale bar represents $20 \mu \mathrm{m}$. 
was not observed to be released and bind to neighboring non-transfected cells despite the presence of external PS on the surface of non-transfected cells (Fig. 5c middle panels; white and yellow arrows). The treatment of HeLa cells with SNCEE and DTT prevented externalization of GFP-CRT and PS (Fig 5c, low panels).

The ability of CRT, which is highly negatively charged (pI 4.46), to interact specifically with negatively charged PS has not been reported. To determine if the interaction of CRT with cell phospholipids was due to direct binding to PS, fulllength, N-C and P domains of CRT conjugated with fluorescein isothiocyanate (FITC) and annexin V conjugated to phycoerythrin (PE) were incubated with the neutrally charged phosphatidylcholine (PC) and PC/PS-containing liposomes, then analyzed by flow cytometry. In the presence of $\mathrm{Ca}^{2+}$, annexin $\mathrm{V}$ bound to approximately 55\% of PS-containing liposomes (Fig. 6a) but bound to $<10 \%$ of PC-only

(a)

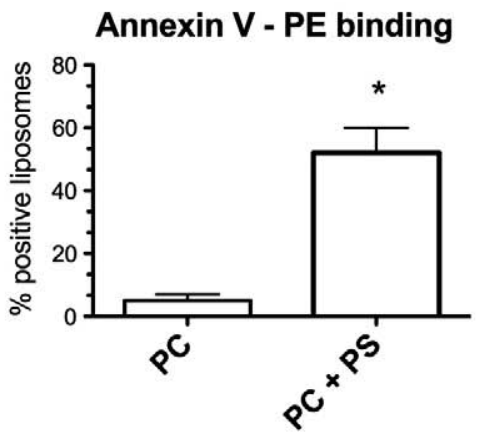

(b)

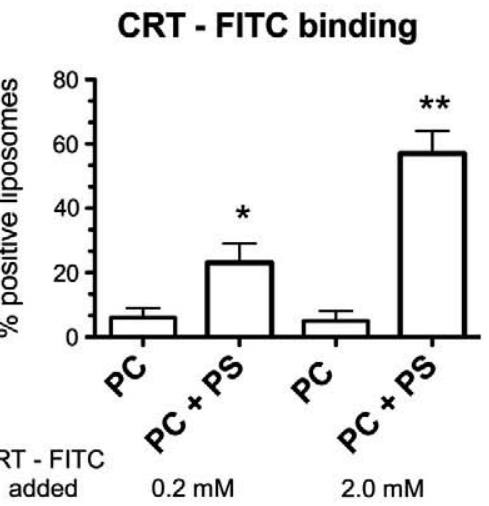

(c)

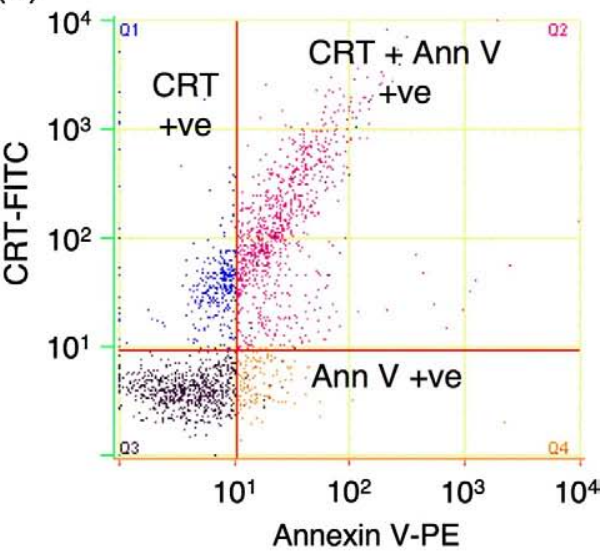

(d)
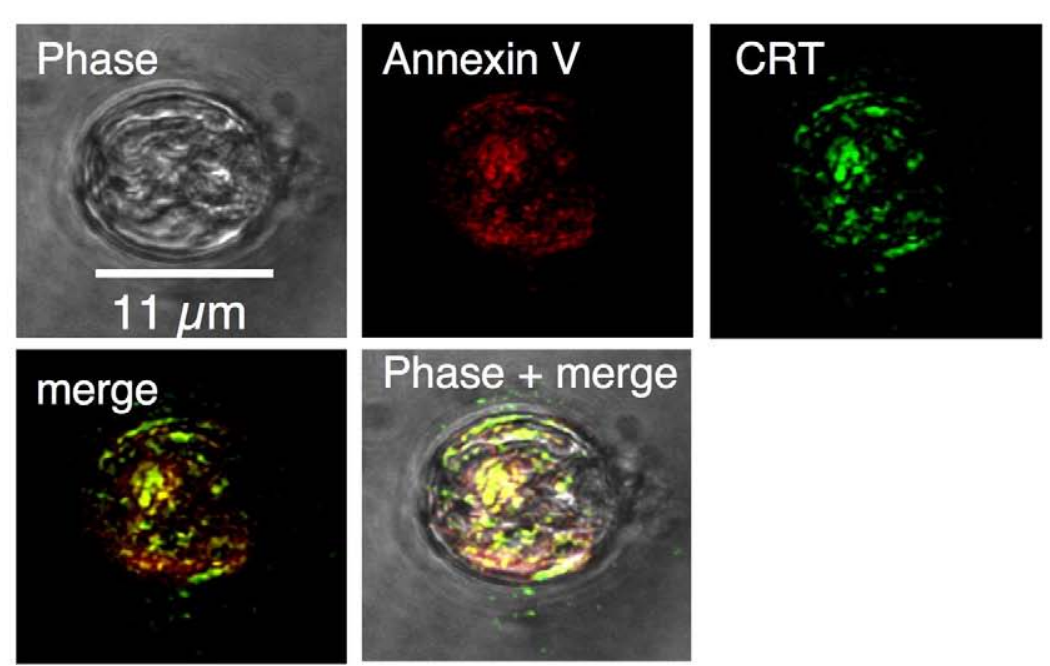

Fig. 6. Demonstration of CRT binding to PS-containing liposomes by flow cytometry and immunofluorescence. (a) The presence of PS on the external surface of liposomes was determined by direct binding to annexin V-PE. (b) CRT-FITC binding to liposomes consisting of $100 \%$ PC or $70 \%$ PC and $30 \%$ PS was detected by flow cytometry. (c) A doublefluorescence plot showing the percentage of liposomes (70\% PC, 30\% PS) positive for annexin V binding alone (lower right quadrant), percentage positive for CRT binding alone (upper left quadrant) and percentage positive for both CRT and annexin V binding (upper right quadrant). (d) Phase and immunoflourescent images of 70\% PC, 30\% PS liposomes (mean diameter $11 \mu \mathrm{m}$ ) incubated with annexin V-PE and CRT-FITC showing the colocalization of CRT binding to PS (merged images). $* p<0.05$, PS and PC versus PC only liposomes, mean \pm SD, Mann-Whitney U test, $n=3$. 


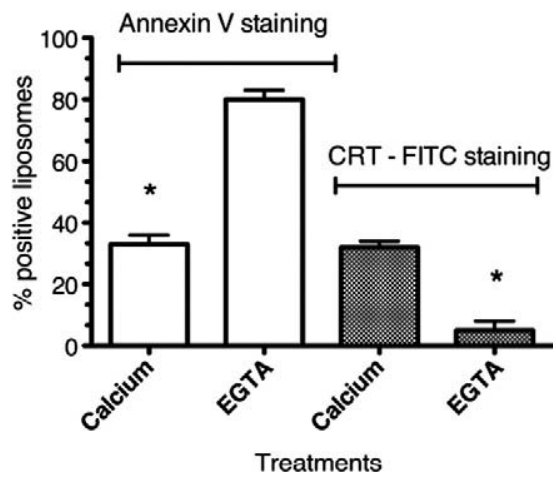

Fig. 7. CRT binding to PS is $\mathrm{Ca}^{2+}$-dependent. Liposomes comprised of 30\% PS and 70\% PC were prepared and suspended in buffer supplemented with $2.5 \mathrm{mM} \mathrm{Ca}^{2+}$ or $5 \mathrm{mM}$ EGTA. The binding of annexin V-PE or CRTFITC was assessed by flow cytometry. In the presence of $\mathrm{Ca}^{2+}$, annexin $\mathrm{V}$ bound specifically to about $35 \%$ of the PS$\mathrm{PC}$ liposomes. However, in depleted $\mathrm{Ca}^{2+}$ buffer, annexin $\mathrm{V}$ was bound to $80 \%$ of the liposomes, because in the presence of low concentrations of $\mathrm{Ca}^{2+}$ annexin $\mathrm{V}$ binds to PC non-specifically: ${ }^{*} p<0.05$, calcium versus EGTA, mean $\pm \mathrm{SD}$, Mann-Whitney $\mathrm{U}$ test, $n=3$ ). In contrast, CRT was bound to approximately $30 \%$ of PS-containing liposomes in the presence of $2.5 \mathrm{mM} \mathrm{Ca}^{2+}$ but to only about $5 \%$ in the presence of EGTA: ${ }^{*} p<0.05, \mathrm{Ca}^{2+}$ versus EGTA, mean $\pm \mathrm{SD}$, Mann-Whitney U test, $n=3$ ).

liposomes. The same liposomes were incubated with $0.2 \mathrm{mM}$ and $2 \mathrm{mM}$ CRT-FITC and both bound to statistically significantly more PS-containing liposomes than PC-alone liposomes (Fig. 6b). Liposomes exposed to annexin V-PE and CRT-FITC simultaneously were assessed for binding by dot plot analysis (Fig. 6c), which demonstrated that approximately $50 \%$ of PS-containing liposomes positive for annexin V were positive also for CRT. Representative visible light and fluorescent micrographs of PC/ PS liposomes are shown in Fig. 6d. Liposomes composed of $70 \%$ PC, 30\% PS bound annexin V (red) and full-length CRT (green) in a colocalized manner, as evident from the merged images that appeared yellow. The distribution of the proteins appeared to occur in a patched or aggregated array up to several micrometers across. Interestingly the $\mathrm{N}-\mathrm{C}$ and P domains of CRT bound very poorly, with $5 \%$ of PS-containing liposomes staining positive for either CRT domain (data not shown). In control experiments, FITC-BSA, IgG-FITC or FITC alone did not bind to liposomes directly. In contrast, FITC-CRT or its domains failed to bind to liposomes composed of only phosphatidylcholine. Nominal amounts of annexin V-PE bound to PC-only liposomes (Fig. 6a). The binding of CRT to PS was determined to be $\mathrm{Ca}^{2+}$-dependent and could be inhibited in the presence of $5 \mathrm{mM}$ EGTA (Fig. 7).

\section{Discussion}

Extracellular CRT is important for essential physiological functions, such as assisting in the recognition of apoptotic cells ${ }^{29-31}$ and opsonizing tumor cells for engulfment by antigen-presenting cells. ${ }^{18}$ Therefore, it is important to explain how CRT is released from cells under various conditions, including cell stress. A number of studies have now begun to explain how CRT might move between organelles. ${ }^{32,33}$ A recent study suggested CRT retrotranslocates from the ER to the cytosol via the nucleus. ${ }^{34}$ Once in the nucleus, CRT is free to interact with proteins with nuclear export signals (NES) and then move into the cytosol, where CRT can be post-translationally modified by incorporation of arginine into the protein in a $\mathrm{Ca}^{2+}$-dependent manner via arginyl transferase activity. ${ }^{6}$ Such modifications, as well as cleavage by proteases, might explain why under certain conditions CRT cannot be detected by standard immunochemistry techniques, e.g. immunoblotting and flow cytometry. Modified forms of the protein in the cytosol or on the extracellular side of the PM might not be recognized by antibodies raised against the nonpost-translationally modified protein or might appear to migrate on SDS-PAGE at different relative molecular masses. In this study, it was interesting to note a relative 4-5 $\mathrm{kDa}$ difference in molecular mass of CRT extracted from the ER compared with the cytosolic and extracellular forms of CRT. Earlier, we showed that CRT is susceptible to proteolytic cleavage dependent on the concentration of $\mathrm{Ca}^{2+12}$ which generates fragments with various molecular masses. Others have detected modified forms of CRT with a reduced relative molecular mass of $6 \mathrm{kDa}$, lacking the KDEL C-terminal sequence, and suggest this might alter the ability of CRT to be retained in the ER. ${ }^{11}$ In other studies, 'ecto-forms' of CRT have been found that migrate in SDS-PAGE consistent with a molecular mass approximately $6 \mathrm{kDa}$ greater than that of 58-60 kDa reported here and by most other studies. Clearly, post-translation modifications of CRT either in the ER or after its translocation to other cellular sites, such as arginylation of CRT in the cytosol, could alter the folding structure or charge of the protein. ${ }^{6}$

In our cell-surface biotinylation immunoblot studies, exoforms of CRT were detected more readily on the surface of FasL-treated apoptotic Jurkat cells. (Fig. 1a). This was confirmed by analysis by flow cytometry, where $24 \%$ of the apoptotic cells (as assessed by annexin V) were also positive for cellsurface CRT. However, $44 \%$ of cells were positive for CRT, which suggests that a proportion of the surface expression of CRT occurs before apoptosis, as suggested by Obeid, ${ }^{35}$ but that additional CRT is released upon PS externalization. Alternatively, the presence of surface-bound CRT on this subpopulation of Jurkat cells staining negative for annexin $\mathrm{V}$ might be as a requirement or action of the many other extracellular physiological roles of CRT.

The retrotranslocation of CRT from the ER to the cytosol is well established. ${ }^{5}$ In this study, activation of the extrinsic pathways (FasL) of apoptosis resulted in the detection of increased cytosolic CRT in Jurkat cells (Fig. 2a and b). The cell has tight 
control over apoptosis and is regulated by activation of $\mathrm{Ca}^{2+}$-dependent enzymes. ${ }^{36}$ Within the cytosolic environment, CRT acts as a $\mathrm{Ca}^{2+}$ buffer controlling the local release of $\mathrm{Ca}^{2+}$. Importantly, cytosolic $\mathrm{Ca}^{2+}$ is involved in the regulation of the amount of PS found on the inner ( $80 \%$ PS) and outer (20\% PS) surfaces of the plasma membrane of healthy cells. ${ }^{37}$ An intriguing result of this study is the demonstration that CRT binds directly to PS in a $\mathrm{Ca}^{2+}$ dependent manner (Fig. 7), where it might provide $\mathrm{Ca}^{2+}$ locally to help regulate the amount of PS on the extracellular leaflet, which acts as an 'eat me' signal. ${ }^{38}$ Both CRT and PS formed punctae at sites of contact with each other in liposomes, which we have seen with CRT on the surface of neutrophils. ${ }^{16}$ This infers CRT can form large oligomers at the cell surface possibly in association with other proteins and clusters of PS. These observations are indicative of CRT clustering in lipid rafts, which we have recently confirmed appears to be the case in mouse lymphoma cells. ${ }^{21}$ In this study, we saw similar surface aggregates in SNCEE-treated HeLa cells transiently expressing GFP-CRT (Fig. 5c, middle panel). Moreover, it is established that Fas/FasL translocate to lipid rafts in T cells upon activation. ${ }^{39}$ We have demonstrated also that extracellular CRT inhibited Fas/FasL interactions on Jurkat T lymphocytes. This could explain, in part, how CRT imparts $\mathrm{T}$ cell resistance to apoptosis by associating with key apoptotic signaling proteins that are concentrated in these lipid rafts. ${ }^{22}$ Interestingly, phosphatidylserine is highly enriched in such rafts and might stabilize raft formation. ${ }^{40}$ Co-capping and co-localization studies have demonstrated that phosphatidylserine is present on the outer surface of rafts in activated lymphocytes. ${ }^{41}$ The suggestion that CRT can down -regulate apoptotic signaling is not novel. Recently, thrombospondin 1 enhancement of CRT/LDL receptor-related protein complex formation has been shown to signal resistance of fibroblasts to apoptosis due to loss of cell adhesion (anoikis). ${ }^{42}$

It is possible that surface CRT is secreted by an unknown mechanism and re-associated with the plasma membrane, rather than flipped through our proposed mechanism. We investigated this possibility using GFP-CRT immunofluorescence (Fig. 5). Representative images that contain transfected cells surrounded by several non-transfected ones are shown in Fig. 5. If the transiently expressed GFPprotein was secreted, we argue that it would be seen on the surface of both the transfected cells and the surrounding non-transfected cells. As shown in Fig. 5c, this is not the case, with GFP-CRT restricted to the surface of transfected cells only. We believe this demonstrates that CRT is not simply secreted, but that it is released in a more controlled manner, and that our proposed flipping could, in principle, account for this process. However, this does not exclude the possibility that CRT is translocated to the cell surface by other mechanisms under different physiological conditions. We did observe a change in the morphology of the SNCEE-treated cells and this might indicate $S$-nitrosylation of some of the cell cytoskeleton proteins, as reported earlier. ${ }^{43}$

We investigated the role of calcium ions in the CRT-PS interaction. It has been known for a number of years that $\mathrm{Ca}^{2+}$ binds directly to PS, inducing the formation of PS aggregates. ${ }^{44}$ Therefore, it is possible that the colocalization of CRT and annexin V may be due to annexin V binding directly to PS, while negatively charged regions of CRT bind electrostatically via $\mathrm{Ca}^{2+}$, to the same aggregates. Alternatively, it has been calculated that the $36 \mathrm{kDa}$ annexin $\mathrm{V}$ molecule binds to both PC/PS vesicles and cells with a similar stoichiometry in which 40 PS molecules are required to bind to a single annexin $\mathrm{V}$ molecule in a $\mathrm{Ca}^{2+}$-dependent manner. ${ }^{45}$ In our study, CRT binding to PS is $\mathrm{Ca}^{2+}$-dependent and is inhibited by EGTA (Fig. 7). The co-localization of CRT and annexin $\mathrm{V}$ binding to PS as observed in Fig. $6 \mathrm{~d}$ can be explained by CRT and annexin V binding in close proximity to different PS molecules adjacent to one another, particularly as annexin $\mathrm{V}$ binding and CRT binding to PS-containing liposomes never attained $100 \%$ binding under our experimental conditions (Fig. 6a and b).

The externalization of PS is dependent on the ATP-dependent APLT and inactivation of APLT causes egress of PS from the inner to the outer leaflet of the PM. ${ }^{46}$ The inner leaflet of the PM is predominantly negatively charged ${ }^{47}$ and comprises $10-30 \%$ of PS. It has been shown that pools of PS on the cytosolic side of the cell can serve to dock basic proteins with binding to C2 domains. ${ }^{48}$ CRT would not normally be expected to associate non-specifically with negatively charged PS, as CRT is an acidic protein with high negative charge. However, the globular head contains clusters of amino acids that are hydrophobic and basic in nature and could act as a 'docking' region to PS. However, in this study we did not see preferential binding of the N-C domain (globular head) region of CRT compared with the $P$ domain, suggesting the intact protein is required for binding to PS. A study by Obeid et al. demonstrated that CRT appeared on the surface of tumor cells, before apoptosis, upon exposure to anthracycline drugs and ultraviolet $C$ light. ${ }^{18}$

It has been suggested that CRT and ERP57, which associate in the ER, might translocate together in the same molecular complex. ${ }^{35}$ Human CRT is not glycosylated, ${ }^{12}$ but a recent study investigated the signal mechanisms for release of mutant glycosylated forms of recombinant CRT upon exposure to anti-tumor drugs. ${ }^{49}$ These artificial $N$-glycosylated mutant CRT species appeared to be exocytosed through a Soluble NSF Attachment Protein (SNARE)-dependent pathway, suggesting glycosylated CRT, if it existed, would traffic through a conventional secretory pathway in which exocytic vesicles have to fuse with the plasma membrane. The assembly of SNARE complexes to allow vesicles to contact the inner layer of the cell membrane and allow their fusion is dependent on local levels of $\mathrm{Ca}^{2+}$ and, again, CRT might act as a $\mathrm{Ca}^{2+}$ buffer during this process. The trafficking of CRT by the secretory 
pathway or by retrotranslocation from the ER to the cytosol would bring CRT into close proximity with the inner leaflet of the plasma membrane in close association with PS. Using a novel system, we tested if the outward flipping of PS led to the surface expression of CRT, independent of caspase 3 activation and apoptosis. We used the transnitrosation reagent SNCEE which is known to inhibit the activity of the PS externalization regulatory enzyme APLT and activate scramblase by enhanced modification of one or more $\mathrm{SH}$ groups. ${ }^{50}$ We observed elevated PS externalization and CRT surface expression in a caspase 3-independent manner (Fig. 4c). Both CRT and PS extracellular expression were reversed with DTT (Fig. 4), presumably because DTT can de-nitrosylate $S$-nitrosylated proteins in live cells and might contribute to rejuvenating APLT activity. ${ }^{51}$ In contrast, the induction of FasL-induced apoptosis caused PS and CRT externalization (Fig. $4 \mathrm{~b}$ and $\mathrm{d}$ ) in a caspase 3-dependent manner (Fig. 4c). Taken together, these observations argue that nitrosative stress can regulate PS externalization and CRT release by inhibiting APLT. However, scramblases are also thought to influence PS externalization. The general dogma for externalization of PS on the outer membrane is for APLT inhibition to occur together with activation of phospholipid scramblase 1 (PLSCR1). APLT is known to regulate the amount of PS on the outer membrane by aiding the return of externalized PS to the inner membrane. A role for activation of PLSCR1 in equilibrating phospholipids (PL) across the membrane, and in particular enhancing PS externalization is debatable. One report has suggested that the main influential partner in PS externalization, at least in FasL-mediated apoptosis, is APLT, with PLSCR activation playing a minor role. $^{52}$ There is evidence that PLSCR1 is not necessary for maintaining a difference in the concentrations of PS in the internal and external leaflets. In a recent mouse blood platelet study, homozygous deletion of PLSCR failed to prevent PS externalization. ${ }^{53}$

Our model system used a synthetic S-nitrosthiolbased NO donor to release NO intracellularly. Within cells, it has been suggested that $\mathrm{NO}$ is available as an $S$-nitrosothiol store that is released in a $\mathrm{Ca}^{2+}$-dependent manner, rather than by de novo synthesis of NO by NOS. ${ }^{54}$ The mechanism of APLT inhibition might be dependent on a transnitrosylation reaction, as opposed to a nitrosylation reaction. The $\mathrm{Ca}^{2+}$-dependent release of $\mathrm{NO}$ might give rise to nitrosylating agents, such as $\mathrm{N}_{2} \mathrm{O}_{3}$, that react with the active sites of cysteines of APLT, thereby inhibiting the enzyme. In such an environment, CRT could act as a source of $\mathrm{Ca}^{2+}$; moreover, the direct interaction of CRT with various isoforms of NOS has been shown to increase the catalytic activity of the enzyme resulting in an increase in NO bioavailability. 7,8

Many proteins involved in inflammation and cytoprotection are secreted by caspase-1-dependent and non-dependent 'unconventional' protein secretion. ${ }^{55}$ Mature CRT lacks a leader sequence and evidence from this study confirms secretion occurs quickly after activation of cell stress and apoptosis, at concentrations that cannot be accounted for by necrosis (as monitored by lactate dehydrogenase activity in our earlier study). ${ }^{22}$ CRT clearly has a number of extracellular functions in tissue repair, ${ }^{17}$ angiogenesis $^{56}$ and focal adhesion disassembly, ${ }^{30}$ and its extracellular expression might be by unconventional means. Here, we report a mechanism by which native CRT can be expressed on the surface of cells. Importantly, it shows for the first time a direct interaction of CRT and PS in a $\mathrm{Ca}^{2+}$ dependent manner. When PS 'flips' to the cell surface on inhibition of APLT by intracellular NO release, it does so in a caspase 3-independent manner and in association with CRT. The surface expression of CRT is correlated precisely with this process.

In summary, this study reveals a physiological regulation of CRT release from cells that is redoxbased. Once released from cells, CRT has a role in many physiological processes, including adhesion, apoptotic cell clearance and tumor cell recognition. Thus, this study demonstrates, in part, that nitrosative stress resulting in the nitrosylation of APLT causes CRT externalization in association with PS, and hence provides a partial explanation as to how CRT can be released from cells in a manner that is not associated with caspase-dependent apoptotic pathways.

\section{Materials and methods}

\section{Cell culture}

Jurkat and HeLa cells were grown in RPMI-1640 medium and D-MEM medium, respectively, both supplemented with $10 \%(\mathrm{v} / \mathrm{v})$ fetal calf serum and $1 \%$ penicillin and $1 \%$ streptomycin.

\section{Bacterial strains and preparation of recombinant full-length and N-C and P domains of calreticulin}

Human CRT (1.2 kb) cDNA in pBluescript lacking the leader sequence was amplified by PCR using the forward primer:

\section{5'-GAT CCT CGA GAG CCC GCC GTC TAC TTC AAG} GAG-3'

and the reverse primer:

\section{5'-GAT CAA GCT TCT A CT ACA GCT CGT CCT CA TGG CCT GGCC-3'}

The forward primer contained a $5^{\prime} \mathrm{XhoI}(\mathrm{C} \Downarrow \mathrm{TC}$ GAG) restriction site and the anti-sense primer contained a $5^{\prime}$ HindIII (A $\Downarrow$ AG CTT) cleavage site. The cDNA was subcloned into XhoI and HindIII restriction sites of the pET32 vector (Novagen, UK). An N-C-domain construct that lacked the P-domain was made in a stepwise PCR/ ligation reaction using the pRSET (Invitrogen) vector as a 
carrier vector. pRSET was used as it provides numerous inframe restriction sites that could be used in this restriction strategy. First, the N-domain lacking the leader sequence was amplified using the forward primer:

$$
\begin{aligned}
& \text { 5' -GATC CTC GGA GCC CGC CGT CTA CTT CAA } \\
& \text { GGA G-3' }
\end{aligned}
$$

and the reverse primer:

\section{5'-GATC CTG CAG TTC CAA GGA GCC GGA CTC CAC CAC CTG-3'}

This product, with a $5^{\prime}$ XhoI site and a 3' PstI site (CTG $C A \Downarrow G)$, was cloned into the respective sites in the pRSET vector. The $\mathrm{C}$-domain was then amplified using the forward primer:

\section{5'-GATC CTG CAG TAT GAT AAC TTT GGC GTG CTG GGC-3'}

and the reverse primer:

\section{5'-GATC AAG CTT CTA CAG CTC GT GTC CTT GGC CTG GCC-3'}

This product, containing a $5^{\prime}$ PstI site and a $3^{\prime}$ HindIII site, was then cloned downstream of the $\mathrm{N}$-domain in pRSET. The complete NC cDNA was then amplified from this carrier vector using the forward primer:

\section{5'-GAT CCT CGG GAG CCC GCC GTC TAC TTC AAG GAG-3'}

and the reverse primer:

\section{5'-GAT CAA GCT TCT ACA GCT CGT CCT TGG CCT GGCC-3'}

and was ligated into the pET32b vector using the $5^{\prime}$ XhoI and $3^{\prime}$ HindIII sites. Positive constructs, were selected by restriction digestion with $\mathrm{XhoI}$ and HindIII. The $\mathrm{P}$ domain was amplified from a pEGFP construct as a template using the forward primer:

\section{5'-GACT CTC GAG GAC GAT TGG GAC TTC CTG CCA CCC AAG-3'}

and the reverse primer:

\section{5'-GATC AAG CTT GGC ATA GAC ACT GGG ATC GGG AGA-3'}

ligated into the pET32b vector using the $5^{\prime}$ Sall and 3 HindIII restriction sites. The ligated constructs were all transformed into BL21 (DE3)-R3/R Rosetta bacteria.

Colony scrapes of BL21(DE3)-R3/R Rosetta bacteria transformed with CRT-pET32 constructs were inoculated in $200 \mathrm{ml}$ of $\mathrm{LB}+\mathrm{Amp}(50 \mathrm{mg} / \mathrm{ml})$ and incubated at $37^{\circ} \mathrm{C}$ in a shaking incubator until the cells were in log phase with an optical density of 0.6 at $600 \mathrm{~nm}$. The culture was induced to generate protein by the addition of IPTG to $1 \mathrm{mM}$ final concentration). Induced bacteria were incubated at $37^{\circ} \mathrm{C}$ for $2 \mathrm{~h}$ to allow accumulation of expressed recombinant protein. The bacteria were then pelleted and protein isolated as described. ${ }^{57}$
For expression of full-length GFP-CRT, the CRT constructs were made with forward primer:

\section{5'-GATC CTC GGG AGC CCG CCG TCT ACT TCA AGG AG-3'}

and reverse primer:

\section{5'-GATC AAG CTT CTA CAG CTC GTC CTT GGC CTG GCC-3'}

The construct was amplified using a $p U C-C R T$ construct reported earlier as a template. ${ }^{57}$ Constructs were cloned into the pEGFP (BD Biosciences) and mammalian expression vectors and used for transient transfections. Control constructs of GFP were transiently transfected into HeLa cells using Lipofectamine ${ }^{\mathrm{TM}} 2000$ (Invitrogen) according to the manufacturer's instructions.

\section{Induction of apoptosis in human cells}

Apoptosis was induced in Jurkat cells by incubation with $25 \mathrm{ng} / \mathrm{ml} \mathrm{FasL}$ for $4 \mathrm{~h}$. The apoptotic status of cells was assessed by annexin V/7-AAD staining, caspase 3 activation and immunofluorescence analysis of nuclear fragmentation and ER blebbing. HeLa cells $\left(1 \times 10^{4}\right.$ cells/well $)$ were plated in eight-well chamber slides and grown for $3 \mathrm{~h}$ at $37^{\circ} \mathrm{C}$. Transient transfections were performed using Lipofectamine 2000 according to the manufacturer's instructions. ${ }^{16,57}$ Briefly, HeLa cells were transfected with $1 \mu \mathrm{g}$ of of GFPCRT cDNA. The cells were incubated overnight at $37^{\circ} \mathrm{C}$, washed with PBS and then fed with DMEM (untreated) or DMEM containing $1.0 \mathrm{mM} \mathrm{H}_{2} \mathrm{O}_{2}$ for $6 \mathrm{~h}$.

\section{Fluorescence microscopy}

A Nikon TE2000U microscope $(100 \times$ objective) with a triple fluorescence filter wheel and equipped with a Hamamatsu CCD camera, was used for image acquisition. Deconvolution analysis was carried out using Openlab 4.4 software and figures were constructed using Adobe Photoshop 5.5. Fluorescence imaging was achieved using FITC-conjugated CRT, and PS was detected via its binding to annexin $\mathrm{V}$ conjugated to phycoerythrin (PE). We also used the GFP-CRT construct explained above, to study the relocation of CRT in the presence and in the absence of SNCEE.

\section{Subcellular fractionation and extracellular release of endogenous CRT}

Release of endogenous CRT from untreated FasLtreated Jurkat cells was examined by detecting CRT in the cell medium by immunoblotting using rabbit antihuman CRT antisera (PA3-900, Affinity Bio-Reagents. Untreated and FasL-treated Jurkat cells were exposed to selected concentrations of digitonin that either permeabilized the PM alone $(0.005 \%(\mathrm{w} / \mathrm{v})$ digitonin $(50 \mu \mathrm{g} / \mathrm{ml}))$ or solubilized all membranes $(0.05 \%(\mathrm{w} / \mathrm{v})$ digitonin $(500 \mu \mathrm{g} / \mathrm{ml})) .{ }^{34}$ The supernatants from the cell preparations were recovered. Supernatants from equal numbers of cells corresponding to equal amounts of protein $(30 \mu \mathrm{g})$ were determined by the Bradford protein assay and by nanodrop spectrophotometry (NanoDrop ND-8000, Nanodrop Technologies, DE). The protein fractions of intact untreated cells, digitonin-permeabilized cells and 
the digitonin-release fractions were analyzed by SDSPAGE and immunoblotted with primary antibodies against CRT, PDI, calnexin and KDEL. Peroxidase-labeled secondary antibodies were detected by chemiluminescence with a Chemidoc ${ }^{\mathrm{TM}}$ imager (Bio-Rad Laboratories). The relative amounts of CRT and marker proteins released from fully permeabilized cells or PM-alone permeabilized cells were determined by densitometric analysis of the digital images using Quantity One ${ }^{(B)}$ software (Biorad).

\section{Biotinylation and purification of cell-surface membrane proteins}

Surface proteins on resting and apoptotic HeLa and Jurkat cells were biotinylated and isolated according to the manufacturer's instructions (product no. 89881, Pierce). Briefly, Jurkat cell types were grown and left unstressed or treated with $25 \mathrm{ng} / \mathrm{ml}$ FasL for $4 \mathrm{~h}$. For each set of experimental conditions, cells at a concentration of $1 \times 10^{7} /$ $\mathrm{ml}$ were labeled with sulfo-NHS-biotin, a hydrophilic reagent that cannot penetrate the plasma membrane. Cells were added to lysis buffer at $4{ }^{\circ} \mathrm{C}$ and the cell lysates were centrifuged at $10,000 \mathrm{~g}$ for $2 \mathrm{~min}$. Biotin-labeled external plasma membrane proteins within the clarified supernatant were concentrated, affinity-purified, and eluted from NeutrAvidin ${ }^{\mathrm{TM}}$ gel bead columns.

\section{Immunoblot analysis}

All protein samples were adjusted to equal concentrations and were subjected to reducing SDS-PAGE $(10 \%$ (w/ v) polyacrylamide gels) in Tris-glycine buffer and blotted onto polyvinylidene fluoride membranes in transblot buffer (25 mM Tris, $192 \mathrm{mM}$ glycine, 10\% (v/v) methanol). Blots were blocked in 5\% (w/v) milk powder in PBS $/ 0.1 \%$ $(\mathrm{v} / \mathrm{v})$ Tween 20 overnight and incubated with commercial rabbit polyclonal antibodies against biotin (Abcam Ltd. ab34645), CRT (Affinity Bioreagents, PA3-900), PDI (Stressgen, SPA-890) or commercial mouse monoclonal anti-human antibodies against calnexin (Santa Cruz Biotechnology, sc-46669), KDEL peptide (QED Bioscience Inc., 11076-50), or Hsp70/Hsc70 HRP (Cambridge Biosciences, SPA-757). Goat anti-mouse IgG-HRP (Santa Cruz, sc2060) and goat anti-rabbit IgG HRP (Santa Cruz, sc2054) were used as secondary antibodies. Chemiluminescence signal detection of the targeted proteins was done with an ECL substrate and images were captured with a Chemidoc XS imager (Bio-Rad).

\section{Interaction of FITC-CRT with lipids}

Multilammelar liposomes were generated from either pure 1-palmitoyl-2-oleoyl-sn-glycero-3-phosphocholine or from a mixture of 70\% 1-palmitoyl-2-oleoyl-sn-glycero-3phosphocholine and $30 \%$ 1-palmitoyl-2-oleoyl-sn-glycero3-phospho-L-serine (Avanti Polar Lipids Inc.). Lipid mixtures were made from $10 \mathrm{mg} / \mathrm{ml}$ stock solutions in chloroform and stored at $-20^{\circ} \mathrm{C}$. All pieces of apparatus used to prepare the liposomes were cleaned and sterilized by immersion in an ultrasound bath in water, autoclaved, then immersed in an ultrasound bath in ethanol and finally rinsed ten times in chloroform. The liposome mixture was drawn into a Hamilton syringe and five drops $(\sim 200 \mu \mathrm{l})$ of solution were spread gently onto the roughened side of a small Teflon plate (approximately $1 \mathrm{~cm}^{2}$ ) using the syringe needle. The Teflon plate was then placed into a small glass bottle, with the roughened side of the plate face up. The bottle was placed into a vacuum desiccator and a small piece of filter paper was placed on top of the bottle, which remained in the desiccator overnight to allow all the chloroform evaporate. The bottle was removed from the desiccator and $40 \mu \mathrm{l}$ of ultrapure sterile water was gently placed next to the Teflon plate in the bottle, ensuring the water did not go onto the top face of the Teflon plate where the lipids were. The bottle was sealed and placed in an oven at $37^{\circ} \mathrm{C}$ for $2 \mathrm{~h}$ to allow the lipids to rehydrate. The swelling solution was either $0.1 \mathrm{M}$ sucrose, $10 \mathrm{mM}$ Hepes, $140 \mathrm{mM} \mathrm{NaCl}$ and $2.5 \mathrm{mM} \mathrm{CaC1}_{2}, \mathrm{pH} 7.4$ for incubation in the presence of $\mathrm{Ca}^{2+}$, or $0.1 \mathrm{M}$ sucrose, $10 \mathrm{mM}$ Hepes, $140 \mathrm{mM} \mathrm{NaCl}, 5 \mathrm{mM}$ EGTA, pH 7.4 for incubation in the absence of free $\mathrm{Ca}^{2+}$. The swelling solution was degassed and incubated at $37^{\circ} \mathrm{C}$ for $2 \mathrm{~h}$. The bottle was removed and $2 \mathrm{ml}$ of the swelling solution was passed gently down the side of the bottle onto the Teflon plate, ensuring that the lipids were not washed off. The bottle was sealed and incubated at $37{ }^{\circ} \mathrm{C}$ for $48 \mathrm{~h}$, whereupon the liposomes formed and were ready for use.

Human full-length recombinant CRT, along with the N$\mathrm{C}$ domain and $\mathrm{P}$ domain of CRT, were conjugated to FITC, using the fluorotag FITC conjugation procedure (Sigma, Dorset, UK). The ratio of mol FITC bound/mol CRT was determined to be approximately $3: 1$. Then various concentrations of lipids and annexin V-PE or CRT-FITC were incubated as described in Results.

\section{Synthesis of SNCEE, cell treatment with SNCEE and measurement of caspase 3 activation}

SNCEE was prepared as described. ${ }^{24}$ Jurkat cells or HeLa cells were incubated for $30 \mathrm{~min}$ at $37^{\circ} \mathrm{C}$ in medium alone, or treated with $600 \mu \mathrm{M}$ SNCEE or treated with $600 \mu \mathrm{M}$ SNCEE, $5 \mathrm{mM}$ DTT. The caspase 3 activity assay was done with the CaspACETM assay system (Promega) according to the manufacturer's instructions. The assay utilizes the caspase 3-specific substrate Ac-DEVD labeled with the yellow-green fluorochrome 7-amino-4-methyl coumarin (AMC). Briefly, Jurkat cells to be assessed for caspase activation were untreated or exposed to SNCEE, FasL or both. The cell preparations were then lysed, centrifuged at $16,000 \mathrm{~g}$ for $20 \mathrm{~min}$ at $4{ }^{\circ} \mathrm{C}$. The supernatants were collected and transferred to black-bottomed 96-well plates to which Ac-DEVD-AMC was added. Caspase 3 activity was measured after incubation for $1 \mathrm{~h}$ at $37^{\circ} \mathrm{C}$ using a BMG labtech PHERAstar plate reader (Aylesbury, UK) at an excitation wavelength of $360 \mathrm{~nm}$ and an emission wavelength of $460 \mathrm{~nm}$.

\section{Acknowledgements}

We thank Dagmara Szestakowska for doing the pilot work for this study. This work was supported by Arthritis Research UK grants E0521, E0543, 17231, 17966 and 16537. PW, PE are grateful for support in the form of a European Union FP7 Marie Curie ITN grant (no. 215009). P.J.Y. and R.M. were supported by the Vandervell Foundation. P.J.Y. and D.J.S. are grateful for support by grants from Fight SMA and the SMA Trust. P.J.Y. and P.E. are thankful for a grant from the Northcott Devon Medical Foundation which funded the cloning work in this study. S.J. is supported by UK MRC grant 
(G0400389). J.T. thanks PMS for a PhD studentship. We thank Drs Tyurina and Stoyanovski of the University of Pittsburgh for advice on SNCEE synthesis and Dr Giles Cory for critical reading of the manuscript.

\section{References}

1. Fliegel, L., Burns, K., MacLennan, D. H., Reithmeier, R. A. \& Michalak, M. (1989). Molecular cloning of the high affinity calcium-binding protein (calreticulin) of skeletal muscle sarcoplasmic reticulum. J. Biol. Chem. 264, 21522-21528.

2. Orth, T., Dorner, T., Meyer Zum Buschenfelde, K. H. \& Mayet, W. J. (1996). Complete congenital heart block is associated with increased autoantibody titers against calreticulin. Eur. J. Clin. Invest. 26, 205-215.

3. Smith, M. J. \& Koch, G. L. (1989). Multiple zones in the sequence of calreticulin (CRP55, calregulin, HACBP), a major calcium binding ER/SR protein. EMBO J. 8, 3581-3586.

4. Johnson, S., Michalak, M., Opas, M. \& Eggleton, P. (2001). The ins and outs of calreticulin: from the ER lumen to the extracellular space. Trends Cell Biol. 11, 122-129.

5. Afshar, N., Black, B. E. \& Paschal, B. M. (2005) Retrotranslocation of the chaperone calreticulin from the endoplasmic reticulum lumen to the cytosol. Mol. Cell. Biol. 25, 8844-8853.

6. Decca, M. B., Carpio, M. A., Bosc, C., Galiano, M. R., Job, D., Andrieux, A. \& Hallak, M. E. (2007). Posttranslational arginylation of calreticulin: a new isospecies of calreticulin component of stress granules. J. Biol. Chem. 282, 8237-8245.

7. Bansal, S., Gaspari, M., Raj, H. G., Kumar, A., Cuda, G., Verheij, E. et al. (2008). Calreticulin transacetylase mediates the acetylation of nitric oxide synthase by polyphenolic acetate. Appl. Biochem. Biotechnol. 144, 37-45.

8. Patel, J. M., Li, Y. D., Zhang, J., Gelband, C. H., Raizada, M. K. \& Block, E. R. (1999). Increased expression of calreticulin is linked to ANG IVmediated activation of lung endothelial NOS. Am. J. Physiol. 277, L794-L801.

9. Boehm, J., Orth, T., Van Nguyen, P. \& Soling, H. D. (1994). Systemic lupus erythematosus is associated with increased auto-antibody titers against calreticulin and grp94, but calreticulin is not the Ro/SS-A antigen. Eur. J. Clin. Invest. 24, 248-257.

10. Eggleton, P., Ward, F. J., Johnson, S., Khamashta, M. A., Hughes, G. R., Hajela, V. A. et al. (2000). Fine specificity of autoantibodies to calreticulin: epitope mapping and characterization. Clin. Exp. Immunol. 120, 384-391.

11. Hojrup, P., Roepstorff, P. \& Houen, G. (2001). Human placental calreticulin characterization of domain structure and post-translational modifications. Eur. J. Biochem. 268, 2558-2565.

12. Corbett, E. F., Michalak, K. M., Oikawa, K., Johnson, S., Campbell, I. D., Eggleton, P. et al. (2000). The conformation of calreticulin is influenced by the endoplasmic reticulum luminal environment. J. Biol. Chem. 275, 27177-27185.

13. Eggleton, P., Tenner, A. J. \& Reid, K. B. (2000). C1q receptors. Clin. Exp. Immunol. 120, 406-412.

14. England, K. \& Cotter, T. (2004). Identification of carbonylated proteins by MALDI-TOF mass spectros- copy reveals susceptibility of ER. Biochem. Biophys. Res. Commun. 320, 123-130.

15. Nakamura, K., Bossy-Wetzel, E., Burns, K., Fadel, M. P., Lozyk, M., Goping, I. S. et al. (2000). Changes in endoplasmic reticulum luminal environment affect cell sensitivity to apoptosis. J. Cell Biol. 150, 731-740.

16. Donnelly, S., Roake, W., Brown, S., Young, P., Naik, H., Wordsworth, P. et al. (2006). Impaired recognition of apoptotic neutrophils by the $\mathrm{C} 1 \mathrm{q} /$ calreticulin and CD91 pathway in systemic lupus erythematosus. Arthritis Rheum. 54, 1543-1556.

17. Nanney, L. B., Woodrell, C. D., Greives, M. R., Cardwell, N. L., Pollins, A. C., Bancroft, T. A. et al. (2008). Calreticulin enhances porcine wound repair by diverse biological effects. Am. J. Pathol. 173, 610-630.

18. Obeid, M., Tesniere, A., Ghiringhelli, F., Fimia, G. M., Apetoh, L., Perfettini, J. L. et al. (2007). Calreticulin exposure dictates the immunogenicity of cancer cell death. Nat. Med. 13, 54-61.

19. Kishore, U., Sontheimer, R. D., Sastry, K. N., Zaner, K. S., Zappi, E. G., Hughes, G. R. et al. (1997). Release of calreticulin from neutrophils may alter C1qmediated immune functions. Biochem. J. 322, 543-550.

20. Peter, M. E. \& Krammer, P. H. (2003). The CD95(APO1/Fas) DISC and beyond. Cell Death Differ. 10, 26-35.

21. Kepp, O., Gdoura, A., Martins, I., Panaretakis, T., Schlemmer, F., Tesniere, A. et al. (2010). Lysyl tRNA synthetase is required for the translocation of calreticulin to the cell surface in immunogenic death. Cell Cycle, 9.

22. Tarr, J. M., Winyard, P. G., Ryan, B., Harries, L. W., Haigh, R., Viner, N. \& Eggleton, P. (2010). Extracellular calreticulin is present in the joints of rheumatoid arthritis patients and inhibits FasL (CD95L) mediated apoptosis of T cells. Arthritis Rheum. (In Press) doi: 10.1002/art.27602.

23. Campos, C. B., Paim, B. A., Cosso, R. G., Castilho, R. F., Rottenberg, H. \& Vercesi, A. E. (2006). Method for monitoring of mitochondrial cytochrome c release during cell death: Immunodetection of cytochrome c by flow cytometry after selective permeabilization of the plasma membrane. Cytometry A, 69, 515-523.

24. Clancy, R., Cederbaum, A. I. \& Stoyanovsky, D. A. (2001). Preparation and properties of S-nitroso-Lcysteine ethyl ester, an intracellular nitrosating agent. J. Med. Chem. 44, 2035-2038.

25. Winyard, P. G., Knight, I. A., Shaw, F. L., Rocks, S. A., Davies, C. A., Eggleton, P. et al. (2008). Chapter 8 determination of S-nitrosothiols in biological and clinical samples using electron paramagnetic resonance spectrometry with spin trapping. Methods Enzymol. 441, 151-160.

26. de Jong, K., Geldwerth, D. \& Kuypers, F. A. (1997). Oxidative damage does not alter membrane phospholipid asymmetry in human erythrocytes. Biochemistry, 36, 6768-6776.

27. Tyurina, Y. Y., Basova, L. V., Konduru, N. V., Tyurin, V. A., Potapovich, A. I., Cai, P. et al. (2007). Nitrosative stress inhibits the aminophospholipid translocase resulting in phosphatidylserine externalization and macrophage engulfment: implications for the resolution of inflammation. J. Biol. Chem. 282, 8498-8509.

28. Mannick, J. B., Schonhoff, C., Papeta, N., Ghafourifar, P., Szibor, M., Fang, K. \& Gaston, B. (2001). SNitrosylation of mitochondrial caspases. J. Cell Biol. 154, 1111-1116.

29. Gardai, S. J., McPhillips, K. A., Frasch, S. C., Janssen, W. J., Starefeldt, A., Murphy-Ullrich, J. E. et al. (2005). 
Cell-surface calreticulin initiates clearance of viable or apoptotic cells through trans-activation of LRP on the phagocyte. Cell, 123, 321-334.

30. Goicoechea, S., Pallero, M. A., Eggleton, P., Michalak, M. \& Murphy-Ullrich, J. E. (2002). The anti-adhesive activity of thrombospondin is mediated by the N-terminal domain of cell surface calreticulin. J. Biol. Chem. 277, 37219-37228.

31. Ogden, C. A., deCathelineau, A., Hoffmann, P. R., Bratton, D., Ghebrehiwet, B., Fadok, V. A. \& Henson, P. M. (2001). C1q and mannose binding lectin engagement of cell surface calreticulin and CD91 initiates macropinocytosis and uptake of apoptotic cells. J. Exp. Med. 194, 781-795.

32. Mohrluder, J., Stangler, T., Hoffmann, Y., Wiesehan, K., Mataruga, A. \& Willbold, D. (2007). Identification of calreticulin as a ligand of GABARAP by phage display screening of a peptide library. FEBS J. 274, 5543-5555.

33. Shaffer, K. L., Sharma, A., Snapp, E. L. \& Hegde, R. S. (2005). Regulation of protein compartmentalization expands the diversity of protein function. Dev. Cell, $\mathbf{9}$, 545-554.

34. Holaska, J. M., Black, B. E., Love, D. C., Hanover, J. A., Leszyk, J. \& Paschal, B. M. (2001). Calreticulin Is a receptor for nuclear export. J. Cell Biol. 152, 127-140.

35. Obeid, M. (2008). ERP57 membrane translocation dictates the immunogenicity of tumor cell death by controlling the membrane translocation of calreticulin. J. Immunol. 181, 2533-2543.

36. McConkey, D. J. \& Orrenius, S. (1996). The role of calcium in the regulation of apoptosis. J. Leukoc. Biol. 59, 775-783.

37. Dachary-Prigent, J., Pasquet, J. M., Freyssinet, J. M. \& Nurden, A. T. (1995). Calcium involvement in aminophospholipid exposure and microparticle formation during platelet activation: a study using Ca2+ATPase inhibitors. Biochemistry, 34, 11625-11634.

38. Draper, D. W., Harris, V. G., Culver, C. A. \& Laster, S. M. (2004). Calcium and its role in the nuclear translocation and activation of cytosolic phospholipase A2 in cells rendered sensitive to TNF-induced apoptosis by cycloheximide. J. Immunol. 172, 2416-2423.

39. Grassme, H., Jekle, A., Riehle, A., Schwarz, H., Berger, J., Sandhoff, K. et al. (2001). CD95 signaling via ceramide-rich membrane rafts. J. Biol. Chem. 276, 20589-20596.

40. Pike, L. J., Han, X., Chung, K. N. \& Gross, R. W. (2002). Lipid rafts are enriched in arachidonic acid and plasmenylethanolamine and their composition is independent of caveolin-1 expression: a quantitative electrospray ionization/mass spectrometric analysis. Biochemistry, 41, 2075-2088.

41. Dillon, S. R., Mancini, M., Rosen, A. \& Schlissel, M. S. (2000). Annexin V binds to viable B cells and colocalizes with a marker of lipid rafts upon B cell receptor activation. J. Immunol. 164, 1322-1332.

42. Pallero, M. A., Elzie, C. A., Chen, J., Mosher, D. F. \& Murphy-Ullrich, J. E. (2008). Thrombospondin 1 binding to calreticulin-LRP1 signals resistance to anoikis. FASEB J. 22, 3968-3979.

43. Thom, S. R., Bhopale, V. M., Mancini, D. J. \& Milovanova, T. N. (2008). Actin S-nitrosylation inhibits neutrophil beta2 integrin function. J. Biol. Chem. 283, 10822-10834.

44. Hoekstra, D. (1982). Fluorescence method for measuring the kinetics of $\mathrm{Ca} 2+$-induced phase separa- tions in phosphatidylserine-containing lipid vesicles. Biochemistry, 21, 1055-1061.

45. Thiagarajan, P. \& Tait, J. F. (1990). Binding of annexin $\mathrm{V} /$ placental anticoagulant protein I to platelets. Evidence for phosphatidylserine exposure in the procoagulant response of activated platelets. J. Biol. Chem. 265, 17420-17423.

46. Tyurina, Y. Y., Tyurin, V. A., Zhao, Q., Djukic, M., Quinn, P. J., Pitt, B. R. \& Kagan, V. E. (2004). Oxidation of phosphatidylserine: a mechanism for plasma membrane phospholipid scrambling during apoptosis? Biochem. Biophys. Res. Commun. 324, 1059-1064.

47. McLaughlin, S. \& Murray, D. (2005). Plasma membrane phosphoinositide organization by protein electrostatics. Nature, 438, 605-611.

48. Yeung, T., Gilbert, G. E., Shi, J., Silvius, J., Kapus, A. \& Grinstein, S. (2008). Membrane phosphatidylserine regulates surface charge and protein localization. Science, 319, 210-213.

49. Panaretakis, T., Kepp, O., Brockmeier, U., Tesniere, A., Bjorklund, A. C., Chapman, D. C. et al. (2009). Mechanisms of pre-apoptotic calreticulin exposure in immunogenic cell death. EMBO J. 28, 578-590.

50. Zhao, J., Zhou, Q., Wiedmer, T. \& Sims, P. J. (1998). Palmitoylation of phospholipid scramblase is required for normal function in promoting $\mathrm{Ca} 2+$-activated transbilayer movement of membrane phospholipids. Biochemistry, 37, 6361-6366.

51. Stoyanovsky, D. A., Tyurina, Y. Y., Tyurin, V. A., Anand, D., Mandavia, D. N., Gius, D. et al. (2005). Thioredoxin and lipoic acid catalyze the denitrosation of low molecular weight and protein S-nitrosothiols. J. Am. Chem. Soc. 127, 15815-15823.

52. Gleiss, B., Gogvadze, V., Orrenius, S. \& Fadeel, B. (2002). Fas-triggered phosphatidylserine exposure is modulated by intracellular ATP. FEBS Lett. 519, 153-158.

53. Zhou, Q., Zhao, J., Wiedmer, T. \& Sims, P. J. (2002). Normal hemostasis but defective hematopoietic response to growth factors in mice deficient in phospholipid scramblase 1. Blood, 99, 4030-4038.

54. Chvanov, M., Gerasimenko, O. V., Petersen, O. H. \& Tepikin, A. V. (2006). Calcium-dependent release of NO from intracellular S-nitrosothiols. EMBO J. 25, 3024-3032.

55. Keller, M., Ruegg, A., Werner, S. \& Beer, H. D. (2008). Active caspase-1 is a regulator of unconventional protein secretion. Cell, 132, 818-831.

56. Vucenik, I., Passaniti, A., Vitolo, M. I., Tantivejkul, K., Eggleton, P. \& Shamsuddin, A. M. (2004). Antiangiogenic activity of inositol hexaphosphate (IP6). Carcinogenesis, 25, 2115-2123.

57. Young, P., Szestakowska, D., Morse, R., Winyard, P. G., Whatmore, J., Johnson, S. J. \& Eggleton, P. (2006). Purification of human native and recombinant domains of calreticulin: structural and functional implications. Calcium Binding Proteins, 1, 160-169.

58. Morse, R., Shaw, D. J., Todd, A. G. \& Young, P. J. (2007). Targeting of SMN to Cajal bodies is mediated by self-association. Hum. Mol. Genet. 16, 2349-2358.

59. Rocks, S. A., Davies, C. A., Hicks, S. L., Webb, A. J., Klocke, R., Timmins, G. S. et al. (2005). Measurement of S-nitrosothiols in extracellular fluids from healthy human volunteers and rheumatoid arthritis patients, using electron paramagnetic resonance spectrometry. Free Radic. Biol. Med. 39, 937-948. 